\title{
Research on Causes and Preventive Measures of the Distribution Line Tripping
}

\author{
Liu Chuanbo ${ }^{1}$, Liu Qiang ${ }^{1}$, Zhu Bo ${ }^{1}$, Ge Changxin ${ }^{1}$, Xie Xinnan ${ }^{1}$, Yang Yingying ${ }^{1}$, \\ Meng $\mathrm{Yu}^{1}$, Zhang Jingyi ${ }^{1}$, Wang Zixu ${ }^{1}$, Huang Yanhai ${ }^{1}$, Su Hainan ${ }^{2}$, Yang Yue ${ }^{3}$ \\ ${ }^{1}$ Fushun Power Supply Company, Liaoning Electric Power Company Limited, State Grid, China, \\ ${ }^{2}$ Dandong Power Supply Company, Liaoning Electric Power Company Limited, State Grid, China, \\ ${ }^{3}$ Overhaul Branch Company, Liaoning Electric Power Company Limited, State Grid, China,
}

fushunpowersupply@163.com

Keywords: distribution line; distribution transformer; lightning arrester; tripping accident; preventive measure

\begin{abstract}
In this paper, the influence of distribution line tripping is analyzed by means of the combination of distribution line tripping case, from equipment, user influence, external factors and natural factors. Power distribution line tripping accident occurs, which affects the economic benefit of power supply enterprises and the reliability of power supply to customers. This paper analyzes the common causes and preventive measures of distribution line tripping, which is of great significance to reduce the number of trips and improve the reliability of power distribution lines.
\end{abstract}

\section{Introduction}

Distribution line is an important part of power system. $10 \mathrm{kV}$ power distribution line is like a person's blood vessels, blood vessels were injured, light is the impact of health, weight loss of life. $10 \mathrm{kV}$ distribution line safe operation is very important for the user. Distribution line is characterized by "node, wide coverage, long line path," line through complex, a wide range of equipment, and customer power equipment directly connected. At the same time, the distribution line affected by climate, geography, environment and other factors, the situation of power supply is complex. These factors are directly or indirectly affect the safe operation of power distribution lines, resulting in the occurrence of power distribution failures. The cause of power distribution line fault is more complex than that of transmission line[1-3].

\section{The actual situation in Fushun area}

From 2010 to 2014 in Fushun area 10kV distribution line trip event statistics, as shown in the Table 1.

Table 1 Statistical table of trip of Fushun city in recent 5 years

\begin{tabular}{|c|c|c|c|c|c|c|c|}
\hline $\begin{array}{c}\text { Dongzhou } \\
\text { District }\end{array}$ & $\begin{array}{c}\text { Xinfu } \\
\text { District }\end{array}$ & $\begin{array}{c}\text { Wanghua } \\
\text { District }\end{array}$ & $\begin{array}{c}\text { Heibei } \\
\text { District }\end{array}$ & $\begin{array}{c}\text { Kaifa } \\
\text { District }\end{array}$ & Total & $\begin{array}{c}\text { Total } \\
\text { line length }\end{array}$ & $\begin{array}{c}\text { Tripping } \\
\text { rate }\end{array}$ \\
\hline 52 & 63 & 26 & 47 & 49 & 237 & 1394.33 & $17 \%$ \\
\hline 60 & 67 & 33 & 46 & 48 & 254 & 1394.33 & $18.22 \%$ \\
\hline 25 & 31 & 17 & 28 & 27 & 128 & 1394.33 & $9.18 \%$ \\
\hline 37 & 35 & 19 & 34 & 35 & 160 & 1394.33 & $11.47 \%$ \\
\hline 34 & 29 & 16 & 41 & 37 & 157 & 1399.33 & $11.26 \%$ \\
\hline & & & & & & & $13.42 \%$ \\
\hline
\end{tabular}

Trip cause pie chart is shown in figure 1.

The operation and maintenance factor is accounting for $30.26 \%$; the equipment reasons is accounting for 23.68\%; External damage is accounting for $17.11 \%$; Natural causes is accounting for $15.63 \%$; Construction quality is accounting for $10.53 \%$; Other reasons is accounting for $2.79 \%$.

From the chart,we can conclude that in the last 5 years, the average tripping failure rate of $10 \mathrm{kV}$ distribution line is $13.42 \%$.We need to take measures to reduce the occurrence rate of distribution line fault. 


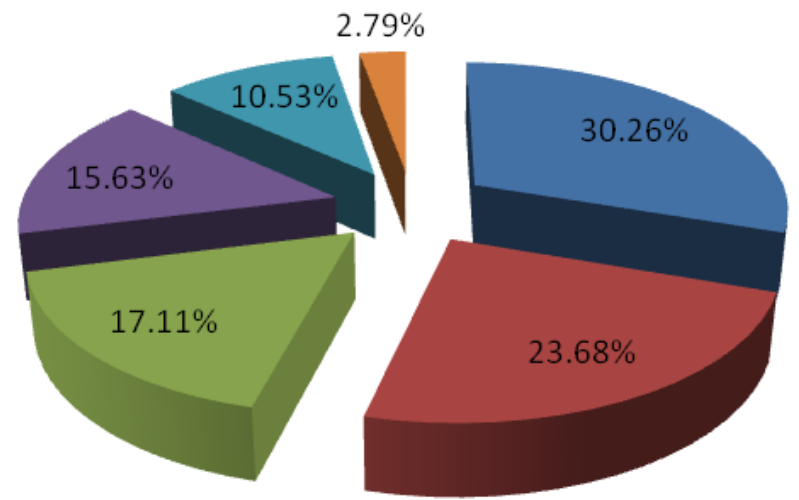

Fig .1 Trip cause pie chart shown

\section{Tripping reason classification}

The safe operation of $10 \mathrm{kV}$ distribution line directly affects the economic benefit of the company. Safe and stable operation is closely related to the high quality service for customers. To take the appropriate technology and management measures to prevent the occurrence of power distribution line accident, timely elimination of defects [4, 5]. At the same time, we can also play the local government, the media and the power of the masses, to increase the safety of power distribution network propaganda, supervision. In order to reduce the occurrence of distribution line accident, to ensure the safe operation of the distribution network, the service of local economic development, the common accidents of $10 \mathrm{kV}$ overhead lines are as follows.

\section{Operation and maintenance work is not in place}

The experience of the new entry personnel in the operation of the power distribution line is insufficient. These personnel in the inspection, is not easy to find the equipment running defects, resulting in the elimination of equipment defects is not timely, accident trip rate will increase.

\section{Equipment reasons}

(1)Equipment running time is long, performance decline

In recent years, fixed assets of equipment has basically achieved the upgrading, but there are a few facilities are not updated, such as distribution transformers, lightning arrester, circuit breaker, long time running high-voltage fuse.

(2)Line fault

Some rural power lines without upgrading. Line lead is fine, the porcelain cross bear runs long, the internal structure of the damage. The above factors can lead to stable performance of the line running down, which is easy to lead to line fault.

(3)User factors

There are still some users continue to use the old equipment, such as the 70's production of power distribution transformers, 60's FS, FZ model. These old equipment problems, will lead to power distribution line fault.

\section{External force damage}

(1)Traffic vehicle factor

The failure of external force is one of the causes of $10 \mathrm{kV}$ distribution line fault, which can be divided into the following categories:

1) Vehicle collision, causing $10 \mathrm{kV}$ power distribution line to fall (tower);

2) Cable is damaged, because the tower inclined or inverted pole (tower);

3) Tower foundation or guyed foundation was emptied, destroyed, cause the collapse of pole (tower);

4) Tools or materials for illegal construction, mistakenly touch the lead, causing the phase of the inter-phase short circuit tripping;

5) The city municipal construction, construction vehicles damaged power tower;

6) Part cement pole, in line across the road without the use of a height of the warning sign, for tall vehicles may be damaged in line, resulting in distribution line cement pole tilt or broken. 
(2)Animal factors

Bird, snake's activity, causes the line short circuit tripping fault.

(3)Debris

The inter-phase short circuit, winding wire, lead to the distribution line trip. The trunk or the tree stems break, the cross is on the lead, causes the inter-phase short circuit, and causes the distribution line trip.

(4)External construction influence

Construction vehicles touch broken branches, the pressure destroyed wire, distribution line tripping. Construction need to tap the ground, damage to cable branch box, distribution line tripping.

\section{Natural factors}

(1) Lightning hazard

$10 \mathrm{kV}$ power distribution lines caused by lightning strikes are very common. Lightning caused by insulator breakdown, burst. Lightning strike leads to wire breaking. Lightning strikes the distribution transformer burned. Lightning accident, and lightning has a great relationship, but the equipment is a defect, analysis of its equipment has the following several reasons:

1) Insulator quality defect. "P 15" and "P 20" type of pin type insulator quality defects. In the last two years, under the conditions of thunderstorm weather. Because of the pin type insulator burst, the $10 \mathrm{kV}$ line or phase short-circuit fault occurs frequently.

2) $10 \mathrm{kV}$ power distribution line lightning protection measures are not sufficient.

In 2002, a lot of power distribution lines are installed with zinc oxide surge arrester. But some long $10 \mathrm{kV}$ distribution lines are not installed line type zinc oxide lightning arrester.

3 ) Wire connector contact is not good. And the groove clamp is often used as the connector of $10 \mathrm{kV}$ line. Some lines are directly wound wiring. And the cable clamp connection or winding connection is not the best way of connecting wire. Contact is not good, can not withstand the impact of a strong lightning current.

4) Arrester grounding device is not qualified. The failure of grounding device, grounding resistance is greater than $10 \mathrm{ohm}$, the discharge capacity is low, and lightning current can not quickly flow into the earth.

(2) Gale

The wind blew down the trees, the branches blew off. Overhead wires or poles broken or crushed will result in line tripping fault.

(3)Heavy rain

The rain washed away the stones near the tower base, causing inverted pole fault.

(4)Pollution flashover

In the early spring season, contamination grades assessment "d or e" region, in the heavy fog weather, prone to pollution flashover story, line caused by the large area of tripping accidents.

\section{Construction quality}

In the installation and commissioning of power equipment, there may exist construction quality problems. Such as cable accident, the accident was mainly caused by the use of the tool of stripping semi conductive layer is damaged the main insulation. Most of the position occurs in the middle of the cable terminal or the cable intermediate joint. For example, transformer accident, transformer in the installation, wiring, wire contact is not good, causing the contact resistance of the joints become big, and eventually lead to thermal breakdown trip.

\section{Other reasons}

Tripping accidents may be caused by the above factors. Can not be qualitative analysis, not easy to judge. There are also some incidents occurred in a moment, operation and maintenance personnel arrived at the scene, according to the scene can not quickly determine the cause of the accident.

\section{Equipment measures}

1) Equipment procurement process, strictly control the quality of products.

2) Line equipment supply manufacturers should focus, such as distribution transformers, drop 
off, insulators, etc. Different manufacturer's supply of different products is not conducive to maintenance.

3) Line and power distribution transformers shall be installed with lightning arrester. Arrester shall comply with the requirements of the regulations. Regular insulation resistance should be test. The leakage current test of $75 \% \mathrm{U} 1 \mathrm{ma}$ and U1ma is carried out regularly. To carry out the replacement of the non - qualified arrester or defective arrester. The insulation line in urban area has been installed with a lightning arrester, which reduces the number of trips to the lightning trip.

4) We can install the short-circuit fault indicator in the $10 \mathrm{kV}$ power distribution line. Even if the $10 \mathrm{kV}$ power distribution line fault occurs, we can quickly find out the fault point and fix it, which reduce the accident loss.

\section{Management measures}

Strengthen the transformation of the circuit, and the design and construction quality control, acceptance of the process must be in accordance with the rules, the non compliance with the requirements of the project shall be ordered to rework.

Strengthen the operation and management of the line, the management staff on a regular training and professional skills training; improve the level of management, to ensure the normal operation of the line.

To strengthen the line inspection work, the line to carry out regular inspections and the line has a planned special and night patrol (infrared). The fault of the patrol is to carefully check the line, and timely to find the cause, to prevent duplication of tripping. The cause of the failure is found to be found to prevent the occurrence of the failure.

GPS mobile patrol management system is to ensure the safe and stable operation of power distribution line. On the distribution line, the fixed point of the inspection, and the operation of the various operating parameters of the record, as the basis for future maintenance and maintenance. Distribution line inspection is an important job to ensure the safety of the transmission equipment, improve the reliability of power supply, and ensure the minimum failure rate of transmission line.

Removing barriers is to ensure the distribution line operation, in line with the provisions of. The operation of the line is not affected by the growth of trees, and the safe distance of the line is ensured.

To strengthen the maintenance of line equipment maintenance, regular electrical equipment testing, maintenance work, and timely processing equipment defects, improves the level of safe operation.

\section{Conclusion}

The level of safety operation of $10 \mathrm{kV}$ power distribution line directly affects the economic benefit of the power supply enterprise and the reliability of the power supply. In short, as long as the line operation and maintenance management work well, take effective measures, so that the line tripping fault to the lowest level, and strive to improve the reliability of power supply line, to ensure the safe, stable operation.

\section{Reference}

[1] Chen Jiabin. Gao Xiaofei. Lightning Protection and Grounding Technology for Electrical Equipment. China Power Press, 2010

[2] Tan Qiong, Li Jinglu, Li Zhiqiang. Lightning Protection Technology for Mountainous Area Network. China Power Press, 2011

[3] Yin Kening. The Design Principle of Transformer. China Power Press, 2010

[4] Ping Shaoxun, Zhou Yufang. Neutral Point Grounding Mode and Operation Analysis of Power System. China Electric Power Press, 2010

[5] Yao huannian, Cao Meiyue. The Resonant Grounded Power System. China Power Press, 2009 